\title{
Impactos Socioambientais Relacionados com a Pesca do Camarão-da-Amazônia Macrobrachium amazonicum (Heller, 1862) na Visão de Pescadores do Rio São José no Município de Abaetetuba/PA
}

\author{
Natanael Charles da Silva ${ }^{1}$, Ércio da Costa Farias Júnior ${ }^{1} \&$ Aldenice de Nazaré da Silva Pereira ${ }^{1}$
}

Recebido em 02/02/2021 - Aceito em 16/09/2021

1 Instituto Federal de Educação, Ciência e Tecnologia do Pará - IFPA, Laboratório de Biodiversidade e Conservação - LABICON, Grupo de Pesquisa em Biodiversidade e Conservação - BIOCON, Abaetetuba/PA, Brasil. CEP: 68.440-000. <natanaelcharles@gmail.com, juniorfarias1717@gmail.com, aldenice.pereira@ifpa.edu.br>.

\begin{abstract}
RESUMO - A pesca pode ser utilizada para o comércio, lazer e fonte de alimentação, sendo uma das principais atividades na Amazônia, responsável pela geração de emprego e renda. Há diversos problemas ocasionados pela interferência humana nessa atividade. Com isso, a presente pesquisa teve por objetivo identificar os principais impactos socioambientais que, na visão dos pescadores locais, estão relacionados com a pesca do camarão-da-amazônia (Macrobrachium amazonicum) no Rio São José, do município de Abaetetuba/PA. Para tanto, foi realizada a aplicação de um questionário dividido em quatro blocos com um total de 66 perguntas, sendo aplicado com 16 pescadores da região em estudo, com o intuito de identificar o perfil socioeconômico destes, bem como investigar aspectos relacionados com a prática da pesca no rio. Os dados obtidos mostram que todos são naturais do município, sendo $25 \%$ pertencentes ao gênero feminino e $75 \%$ ao masculino. Do total, $50 \%$ dos pescadores afirma que o tamanho dos camarões capturados nos últimos anos diminuiu, e $81 \%$ afirma que essa espécie diminuiu muito em quantidade devido à poluição, ao aumento da população em torno do rio e ao elevado número de pescadores. Conclui-se que muitos dos entrevistados ainda vivem em condições socioambientais inadequadas, com ausência de saneamento básico, água potável e sem tratamento de lixo, o que contribui para a poluição do rio, prejudicando assim a espécie e, portanto, a atividade pesqueira.
\end{abstract}

Palauras-chave: Problemas socioambientais; camarão regional; pesca de camarão; conservação.

\section{Socio-environmental Impacts Related to the Fishing of the Amazon Shrimp Macrobrachium amazonicum (Heller, 1862) from the Point of View of Fishermen of the São José River in the Municipality of Abaetetuba/PA}

ABSTRACT - Fishing can be used for trade, leisure and food source, being one of the main activities in the Amazon, responsible for generating employment and income. There are several problems caused by human interference in this activity, thus, this research aimed to identify the main socioenvironmental impacts that, in the view of local fishermen, are related to the fishing of Amazon shrimp (Macrobrachium amazonicum) in the São José River, in the municipality of Abaetetuba/PA. For this, a questionnaire was applied to 16 fishermen in the study area, divided into four blocks with a total of 66 questions, in order to identify their socioeconomic profile, as well as to investigate aspects related to the practice of fishing in the river. The data obtained shows that all of them were born in the municipality, $25 \%$ were female, and $75 \%$ male. Of the total, $50 \%$ of the fishermen said that the size of the shrimp caught in the last years has decreased, and $81 \%$ said that this species has decreased a lot in quantity due to pollution, increase in population around the river, and the high number of fishermen. It is concluded that many of the interviewees still live in inadequate socio-environmental conditions, with no basic sanitation, no drinking water, and no garbage treatment, which contributes to the pollution of the river, thus harming the species and therefore the fishing activity.

Keywords: Socio-environmental problems; regional shrimp; shrimp fishery; conservation.

\section{Impactos Sociales y Ambientales Relacionados con la Pesca del Camarón Amazónico Macrobrachium amazonicum (Heller, 1862) en la Mirada de los Pescadores del Río São José en el Municipio de Abaetetuba/PA}

RESUMEN - La pesca se puede utilizar para el comercio, el ocio y la alimentación, siendo una de las principales actividades de la Amazonía, responsable de generar empleo e ingresos. Son varios los 
problemas provocados por la interferencia humana en esta actividad, por lo que esta investigación tuvo como objetivo identificar los principales impactos sociales y ambientales que, a juicio de los pescadores locales, están relacionados con la pesca de camarón amazónico (Macrobrachium amazonicum) en el río São José, en el municipio de Abaetetuba/PA. Para ello, se aplicó un cuestionario, dividido en cuatro bloques con un total de 66 preguntas, siendo aplicado a 16 pescadores de la región en estudio, con el fin de identificar su perfil socioeconómico, así como investigar aspectos relacionados con la práctica de la pesca. en el rio. Los datos obtenidos muestran que todos ellos son de la ciudad, con un $25 \%$ perteneciente al género femenino y el $75 \%$ al masculino. Del total, el $50 \%$ de los pescadores dijo que había disminuido el tamaño de los camarones capturados en los últimos años, y el $81 \%$ dijo que esta especie había disminuido mucho en cantidad debido a la contaminación, un aumento de la población alrededor del río y la alta. número de pescadores. Se concluye que muchos de los entrevistados aún viven en condiciones socioambientales inadecuadas, con falta de saneamiento básico, agua potable y sin tratamiento de residuos, lo que contribuye a la contaminación de los ríos, perjudicando así a la especie $y$, por ende, a la actividad pesquera.

Palabras clave: Problemas sociales y ambientales; camarón regional; pesca de camarón; conservación.

\section{Introdução}

A pesca é considerada como uma importante fonte de alimento de origem animal com alto valor proteico e como uma prática extrativista, responsável pela geração de emprego e renda para as comunidades litorâneas (Oliveira \& Frédou, 2011).

De acordo com Santos \& Santos (2005), a pesca é considerada ainda uma atividade humana de grande importância na Amazônia, utilizada para o comércio, renda, lazer e fonte de alimentação para a maioria da população, principalmente as que vivem às margens dos rios. Essa região, além de possuir uma vasta diversidade biológica e cultural, também abriga um enorme potencial hídrico bastante desejado (Araújo et al., 2014).

As interferências antrópicas, causadas principalmente como consequência da exploração das águas dos rios, ocasionaram diversos impactos ambientais, em especial, aos recursos pesqueiros que passam a ter sua rota migratória interrompida, acarretando consequências como a redução de algumas populações e do número de espécies (Mérona et al., 2010).

$\mathrm{Na}$ região Norte do Brasil, destaca-se a captura de camarões, que é tradicionalmente executada em áreas marinhas, estuarinas $e$ continentais do estado do Pará como uma importante atividade da produção pesqueira (Silva et al., 2011). Dentre as espécies de camarões mais pescados, Lucena-Frédou et al. (2010) afirmam que o camarão-da-amazônia é o principal camarão de água-doce explorado comercialmente nos estados do Pará e Amapá pela pesca artesanal, onde apresenta uma comercialização significativa.

De acordo com Alcântara \& Kato (2016), o camarão-da-amazônia (Macrobrachium amazonicum, Heller, 1862) é um decápode de água doce com grande importância econômica para a Amazônia. Ressalta-se ainda que essa é a espécie de água doce mais comumente encontrada no Brasil (Costa et al., 2016). Além disso, cerca de 33 espécies desse gênero ocorrem no continente americano, dentre as quais quinze já foram registradas no Brasil (Pinheiro \& Hebling, 1998).

A atividade de captura e posterior comercialização dessa espécie é uma importante fonte de renda para as famílias paraenses (Silva et al., 2017), uma vez que o destino da produção inclui diversos pontos de desembarque no estado do Pará e do Amapá. Esses camarões são distribuídos por intermediários em bares, restaurantes, supermercados, mercados e feiras livres e aos consumidores finais de ambos os estados (Lima \& Santos, 2014).

O município de Abaetetuba, no estado do Pará, é uma região que contribui de forma histórica e cultural para o estado. Possui uma área de grande influência pesqueira, banhada pelo rio Tocantins, cujas águas fazem parte da vida da população. Através dessas águas, a cidade se transformou no mais importante mercado pesqueiro de toda a região (Caetano, 2012).

Desta forma, sendo a pesca artesanal um dos principais destaques do extrativismo e da atividade econômica de grande importância 
para o município, a presente pesquisa objetivou identificar os principais impactos socioambientais que, na visão dos pescadores locais, estão relacionados com a pesca do camarão-da-amazônia (Macrobrachium amazonicum) no rio São José, do município de Abaetetuba/PA.

\section{Material e Métodos \\ Área de estudo}

O município de Abaetetuba, no estado do Pará, encontra-se localizado à margem direita do rio Maratauíra, um dos afluentes do estuário do rio Tocantins, pertencendo a Região de Integração Tocantins (SEMEIA, 2017). Seu principal rio é o rio Pará, fazendo limite a noroeste com os municípios de Muaná e Ponta de Pedras, destacando nele dezenas de ilhas, tais como: Urubuéua, Sirituba, Capim, Compopema, entre outras (FAPESPA, 2016). Além do rio Pará, outros rios possuem grande importância para o município, pelo seu potencial de recursos pesqueiros, como o rio São José (Figura 1), que é o foco de estudo da presente pesquisa.

\section{Mapa de Localização da Área de Estudo}

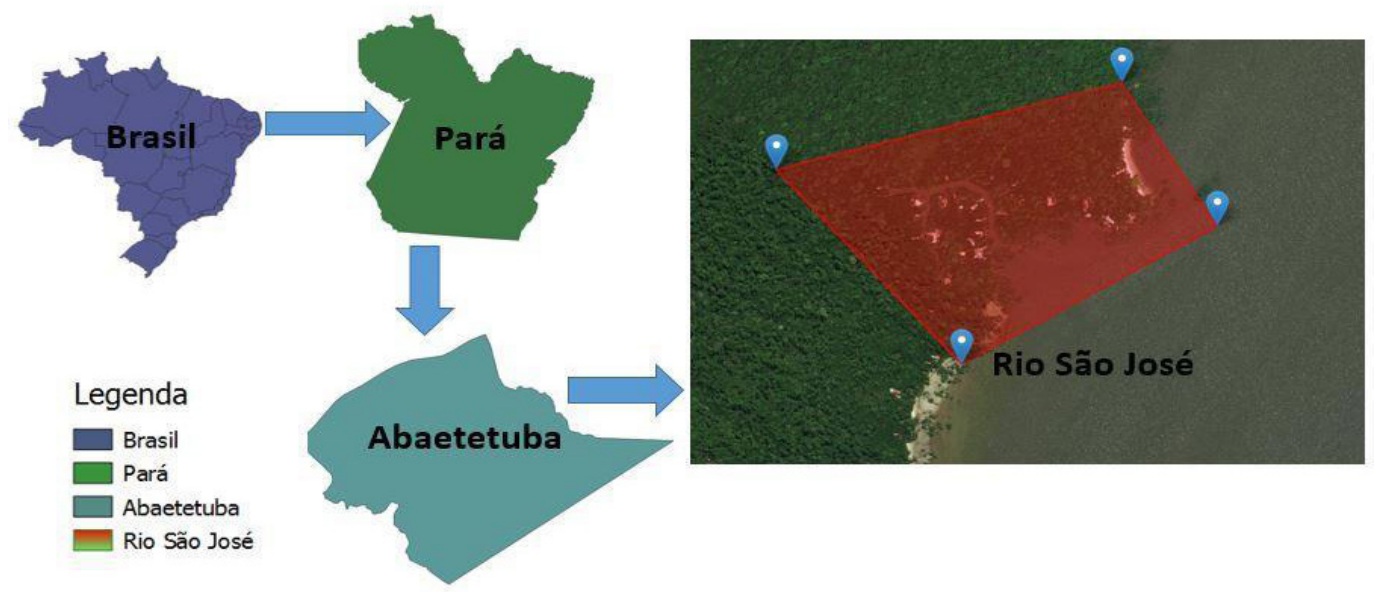

Figura 1 - Mapa de localização da área de estudo.

Fonte: Os autores (2019).

O rio São José é denominado pelos moradores de Igarapé São José. Para chegar à localidade, é necessária cerca de 1 hora de viagem, partindo da frente da cidade de Abaetetuba no bairro São João, utilizando como meio de transporte embarcações marítimas, como, barcos e rabetas. O rio caracteriza-se por ser estreito, com várias árvores à sua margem, contendo apenas uma entrada e desaguando no rio Capim (Figura 2).

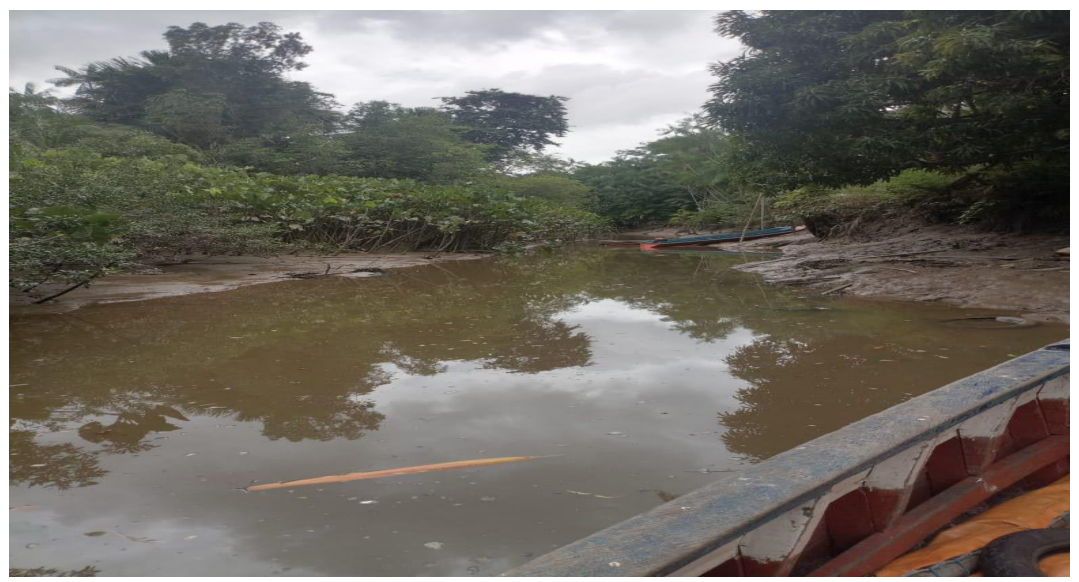

Figura 2 - Entrada do rio São José.

Fonte: Os autores (2019). 
Como o rio é de difícil acesso, utilizam-se barcos pequenos para navegação. Mesmo assim, os barcos só o adentram quando a maré está alta. Na maré baixa, fica impossibilitada a entrada e a saída do local, dificultando inclusive o acesso às casas dos moradores, devido à grande quantidade de lama.

\section{Elaboração, aplicação do questionário e análise de dados}

$\mathrm{O}$ presente trabalho caracteriza-se como uma pesquisa quantitativa e qualitativa, de caráter exploratório, na qual foi realizada uma visita às margens do rio São José e posterior aplicação de um questionário dividido em blocos que abordam aspectos socioambientais relevantes da localidade.
O questionário foi aplicado (Figura 3) a um total de 16 pescadores selecionados de forma aleatória dentre os 22 pescadores que vivem às margens do rio São José, o que compreende uma amostragem de $72 \%$ do total de pescadores do local.

O questionário foi estruturado de acordo com Araújo et al. (2014), composto por 66 questões e dividido em quatro blocos. $\mathrm{O}$ conjunto de perguntas que compõem o bloco I foca em informações voltadas para a identificação do pescador, sendo possível com isso, traçar seu perfil socioeconômico. No bloco II, as informações solicitadas referem-se à prática da pesca do camarão, sendo possível identificar com as respostas fatores que prejudicam o desenvolvimento do mesmo, a interferência no ciclo de vida ou outros impactos na espécie em estudo.

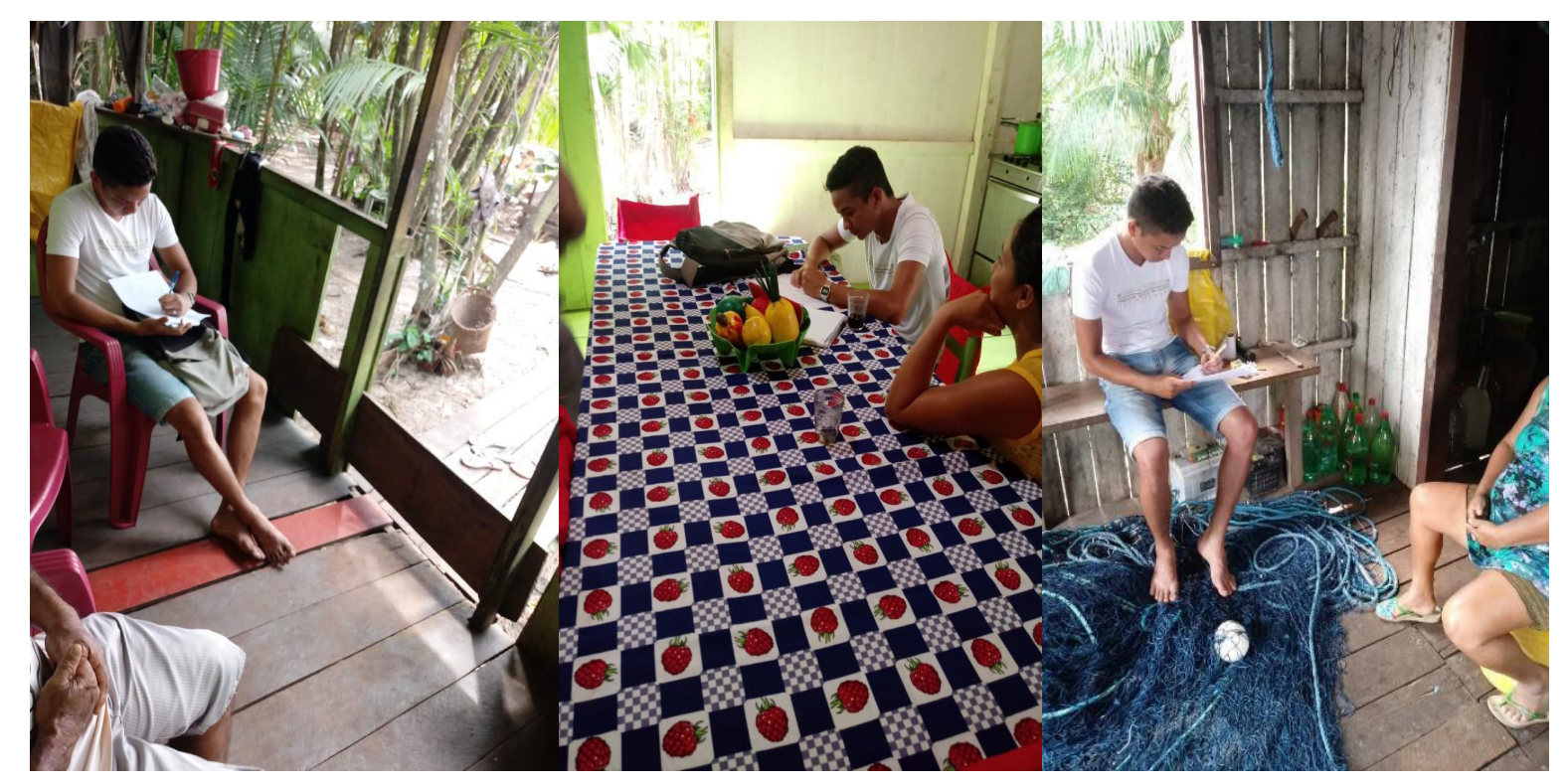

Figura 3 - Aplicação dos questionários aos pescadores. Fonte: Arquivo Pessoal (2019).

No bloco III, buscou-se investigar fatores relacionados à comercialização do camarão pescado na região, e, no IV e último bloco de perguntas, pesquisou-se a respeito de informações sobre infraestrutura, habitação e saúde dos moradores da região, buscando com isso relacionar os fatores em questão com as práticas da pesca e a interferência ambiental realizadas pelos moradores.

Os dados obtidos foram tabulados no programa Excel 2013, analisados e expostos por meio de tabelas e nuvens de palavras, relacionando os dados obtidos na pesquisa com os impactos encontrados na literatura especializada. O mapeamento do local foi realizado no programa QGIS versão 3.8.0 e as nuvens de palavras foram produzidas no site "Wordart.com".

\section{Resultados e Discussão}

Os resultados mostram que todos os entrevistados são naturais do município de Abaetetuba, a maioria são analfabetos e possuem mais de 20 anos de atividade pesqueira. Todos 
aproveitam o período de inverno como época de safra do camarão-da-amazônia e a grande maioria confirma não respeitar o período de defeso. Além disso, foram constatados: a falta de saneamento básico, a desinformação da população sobre questões biológicas do camarão, a instalação de empresas nas proximidades do rio, a superpopulação na comunidade, a poluição e o aumento exagerado da pesca como os principais fatores socioambientais relacionados com a pesca do camarão-da-amazônia no rio São José.

\section{Perfil socioeconômico do pescador do rio São José}

Dos entrevistados, $75 \%$ pertencem ao gênero masculino e $25 \%$, ao feminino, dados estes semelhantes com os obtidos por Zacardi et al. (2014), cuja pesquisa mostra que a idade dos pescadores artesanais variou entre 16 e 74 anos, com mais de $45 \%$ na faixa etária de 45 a 60 anos, sendo a maioria pertencente ao sexo masculino.

De acordo com os dados obtidos (Tabela 1 ), os pescadores entre a faixa etária de 47 a 56 anos é predominante em relação ao número de filhos (11), dados semelhantes foram apresentados por Santos et al. (2011), cuja pesquisa aponta que $53 \%$ são casados e com número de dependentes variando de 4 a 5 pessoas. Esses dados apesar de serem baixos, se comparados quando os pescadores tinham famílias numerosas, ainda estão próximas das características familiares consideradas apropriadas para a melhoria da sua qualidade de vida.

Tabela 1 - Perfil socioeconômico dos pescadores.

\begin{tabular}{|l|c|c|}
\hline Pescadores entrevistados $\mathbf{N}=\mathbf{1 6}$ & \\
\hline$\left(\mathbf{n}^{\mathbf{0}}\right)$ & Idade* & \\
\hline 4 & $17-26$ & \\
\hline 2 & $27-36$ & \\
\hline 6 & $37-46$ & \\
\hline 2 & $47-56$ & \\
\hline 1 & $57-66$ & $\left(\mathbf{n}^{\mathbf{0}}\right)$ \\
\hline 1 & $67-76$ & 4 \\
\hline Sexo & $\mathbf{( \% )}$ & 12 \\
\hline Feminino & 25 & $\left(\mathbf{n}^{\mathbf{0}}\right)$ \\
\hline Masculino & 75 & 4 \\
\hline Estado civil & $\mathbf{( \% )}$ & 7 \\
\hline Casado (a) & 25 & 0 \\
\hline Solteiro (a) & 31,25 & 5 \\
\hline Viúvo (a) & 0 & $\left(\mathbf{n}^{\mathbf{0}}\right)$ \\
\hline União estável & 43,75 & 7 \\
\hline Grau de instrução & $\mathbf{( \% )}$ & 5 \\
\hline Sem alfabetização & 43,75 & 3 \\
\hline Fundamental incompleto & 31,25 & 0 \\
\hline Fundamental completo & 18,75 & 1 \\
\hline Ensino médio incompleto & 0 & 0 \\
\hline Ensino médio completo & 6,25 & 0 \\
\hline Ensino superior incompleto & 0 & \\
\hline Ensino superior completo & 0 & \\
\hline & & \\
\hline
\end{tabular}




\begin{tabular}{|l|l|}
\hline Número de filhos $\left.\mathbf{( n}^{\mathbf{0}}\right)$ & Idade* \\
\hline 0 & $17-26$ \\
\hline 4 & $27-36$ \\
\hline 8 & $37-46$ \\
\hline 11 & $47-56$ \\
\hline 5 & $57-66$ \\
\hline 5 & $67-76$ \\
\hline Pessoas que moram na residência $\left(\mathbf{n}^{\mathbf{0}}\right)$ & Idade* \\
\hline 18 & $17-26$ \\
\hline 8 & $27-36$ \\
\hline 25 & $37-46$ \\
\hline 8 & $47-56$ \\
\hline 4 & $57-66$ \\
\hline 1 & $67-76$ \\
\hline
\end{tabular}

Fonte: Os autores (2019).

* Foi considerada uma geração a cada 10 anos.

Outro trabalho que corrobora com os dados apresentados na tabela é a pesquisa de Sousa et al. (2018), realizada com os pescadores artesanais da ilha do Capim, em Abaetetuba. Esses autores apontam o catolicismo como religião predominante entre os pescadores, destacando ainda que os mesmos consideram a religião como um dos meios de educar os filhos.

Desse modo, essa baixa escolaridade dos pescadores, por consequência, coloca a atividade da pesca não como uma opção, mas como única alternativa de trabalho capaz de garantir a sobrevivência (Nogueira et al., 2017).

De cada família dos entrevistados, todos os integrantes ajudam na atividade pesqueira
(Tabela 2), mesmo aqueles que estudam, realizando-a nos momentos vagos. A atividade foi apresentada a eles por algum membro da família, como o pai, $56,25 \%$; a mãe, $6,25 \%$; um amigo, $6,25 \%$; outro parente, $25 \%$; ou aprendendo a pescar sozinho, 6,25\%. Dados semelhantes são apontados por Dias \& Soares (2018), quando apresentam que $96 \%$ do total de pescadores relacionados a sua pesquisa aprenderam a pescar o camarão com o pai, assim como no trabalho de Santos et al. (2011), que aponta que a prática é exercida por diferentes gerações, o que sugere que a transferência de aprendizado da atividade é passada de pai para filho.

Tabela 2 - Aspectos relacionados ao trabalho dos pescadores por meio da pesca.

\begin{tabular}{|l|c|c|}
\hline Pescadores entrevistados $\mathbf{N = 1 6}$ & $\mathbf{( \% )}$ & Idade* \\
\hline Tempo de pesca (anos) & 25 & $17-26$ \\
\hline 3 a 10 & 12,5 & $27-36$ \\
\hline 13 a 14 & 37,5 & $37-46$ \\
\hline 20 a 36 & 12,5 & $47-56$ \\
\hline 35 a 42 & 6,25 & $57-66$ \\
\hline 45 & 6,25 & $67-76$ \\
\hline
\end{tabular}




\begin{tabular}{|c|c|c|}
\hline Membros que auxiliam na pesca $\left(n^{\circ}\right)$ & $(\%)$ & Idade* \\
\hline 16 & 34,6 & $17-26$ \\
\hline 4 & 8,1 & $27-36$ \\
\hline 16 & 34,6 & $37-46$ \\
\hline 6 & 13 & $47-56$ \\
\hline 3 & 6,4 & $57-66$ \\
\hline 1 & 3,3 & $67-76$ \\
\hline Aprendeu a pescar camarão & $(\%)$ & $\left(n^{\circ}\right)$ \\
\hline Sozinho & 6,25 & 1 \\
\hline Pai & 56,25 & 9 \\
\hline Amigo & 6,25 & 1 \\
\hline Mãe & 6,25 & 1 \\
\hline Parente & 25 & 4 \\
\hline $\begin{array}{l}\text { Além da pesca do camarão exerce outra } \\
\text { atividade }\end{array}$ & $(\%)$ & \\
\hline Não & 18,75 & \\
\hline Sim & 81,25 & \\
\hline Qual? & $(\%)$ & $\left(n^{0}\right)$ \\
\hline Empregada doméstica & 7,7 & 1 \\
\hline Pesca peixe e apanha açaí & 53,8 & 7 \\
\hline Pesca peixe & 30,8 & 4 \\
\hline Apanha açaí & 7,7 & 1 \\
\hline Principais fontes de renda do grupo familiar** & $(\%)$ & $\left(n^{\circ}\right)$ \\
\hline Peixe, camarão e açaí & 68,75 & 11 \\
\hline Peixe e camarão & 25 & 4 \\
\hline Camarão e açaí & 6,25 & 1 \\
\hline Outros & 0 & 0 \\
\hline Renda complementar** & $(\%)$ & $\left(n^{0}\right)$ \\
\hline Aposentadoria & 6,25 & 1 \\
\hline Benefício do governo & 6,25 & 1 \\
\hline Pensão & 6,25 & 1 \\
\hline Benefício do governo e seguro defeso & 81,25 & 13 \\
\hline Outros & 0 & 0 \\
\hline
\end{tabular}

Fonte: Os autores (2019).

* Foi considerado uma geração a cada 10 anos.

** A pergunta poderia ser respondida com mais de uma alternativa.

Os pescadores com a faixa etária de 57 a 76 anos afirmam que trabalham com a atividade há mais de 45 anos, demonstrando que iniciaram a prática muito cedo. Além da pesca do camarãoda-amazônia, $81,25 \%$ dos entrevistados afirmam que exercem outra atividade para auxiliar na renda da família. Lima et al. (2012) afirmam que é muito comum esses trabalhadores complementarem a sua renda com outras atividades extrativistas.
Além disso, Ramires et al. (2012) e Zacardi et al. (2014) reforçam ainda que antes desenvolvida como meio de subsistência, a pesca artesanal já não é mais a única atividade econômica, uma vez que os pescadores desenvolvem outras atividades para complementar a renda da família.

Os pescadores alegam ainda que, além do trabalho com a pesca do camarão e outras 
atividades complementares, todos possuem renda complementar às atividades, como, aposentadoria ou benefício do governo (bolsa família, bolsa escola ou ambos), sendo que a maioria, $81,25 \%$, recebe benefício do governo e seguro defeso.

Sobre este fato, Campos \& Chaves (2014) afirmam que os auxílios fornecidos pelo governo aos pescadores têm por objetivo amparar o pescador artesanal, de forma monetária durante o período de defeso, visto que este fica impedido de retirar seu sustento dos rios. Além disso, o benefício colabora na preservação da reprodução durante o período de defeso de várias espécies de peixe.

Através desta análise do perfil socioeconômico dos pescadores em questão, verifica-se que a pesca do camarão-da-amazônia sozinha já não é mais suficiente para garantir o sustento e qualidade de vida dos pescadores da região. Além disso, o analfabetismo associado à desinformação sobre a importância do período de defeso para a manutenção e o equilíbrio das espécies pescadas estão entre os fatores socioambientais relacionados à pesca do camarãoda-amazônia no rio São José.

\section{Caracterização da pesca do camarão pelos pescadores do rio São José}

No bloco II, foram realizadas perguntas referentes à pesca do camarão, destacando que a principal espécie capturada é o Macrobrachium amazonicum (Heller, 1862), conhecido pelos pescadores como camarão regional, assim como, no trabalho de Costa et al. (2016).

Para a pesca do camarão, são utilizadas embarcações próprias ou alugadas, como cascos, rabetas ou barcos com motor. De acordo com Nogueira et al. (2017), nos municípios pertencentes à microrregião de Cametá (que abrange Abaetetuba, Mocajuba e Igarapé-Miri), a pesca ocorre nos afluentes do rio Tocantins, à jusante da usina hidrelétrica de Tucuruí, e, para tal, são utilizadas pequenas embarcações, com o predomínio de canoas ou montarias movidas a remo ou a vela. $\mathrm{Na}$ atividade é utilizado um apetrecho denominado de matapi (Figura 4), bem como no trabalho de Costa et al. (2016), essas armadilhas possuem a forma de cilindro, fechado por dois cones, e cada lado possui uma abertura em forma de funil para que o camarão entre $e$ não possa mais sair, sendo utilizadas para sua construção talas de jupati (Raphia taedigera), uma palmeira da floresta amazônica (Caetano, 2012).

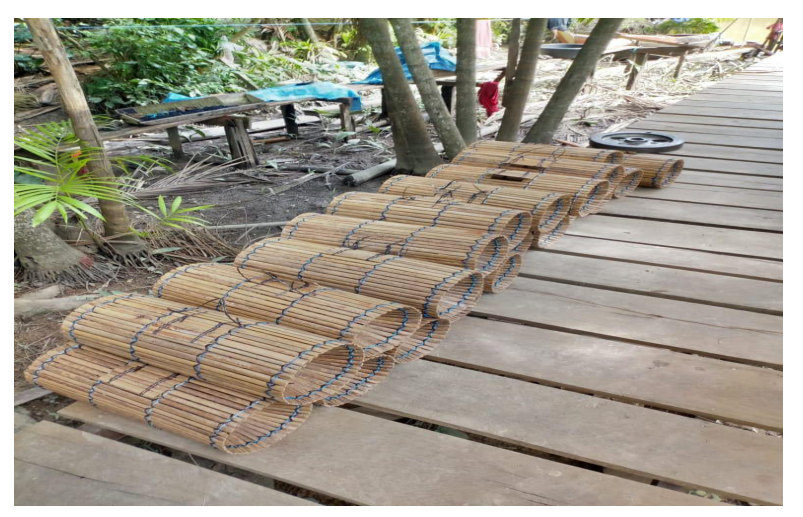

Figura 4 - Armadilha para pesca do camarão do tipo matapi.

Fonte: Os autores (2019).

Esses apetrechos são construídos pelos próprios pescadores, juntamente com suas famílias, bem como é descrito também no trabalho de Moraes (2005) que afirma que o processo de confecção desse instrumento muitas vezes envolve as mulheres e os filhos dos pescadores. Dentro dos matapis, são colocados os chamados "farelo de babaçu" ou farelo do coco babaçu (Orbignya speciosa) (Figura 5) que, segundo Barros (2009), serve como isca para capturar o camarão. 


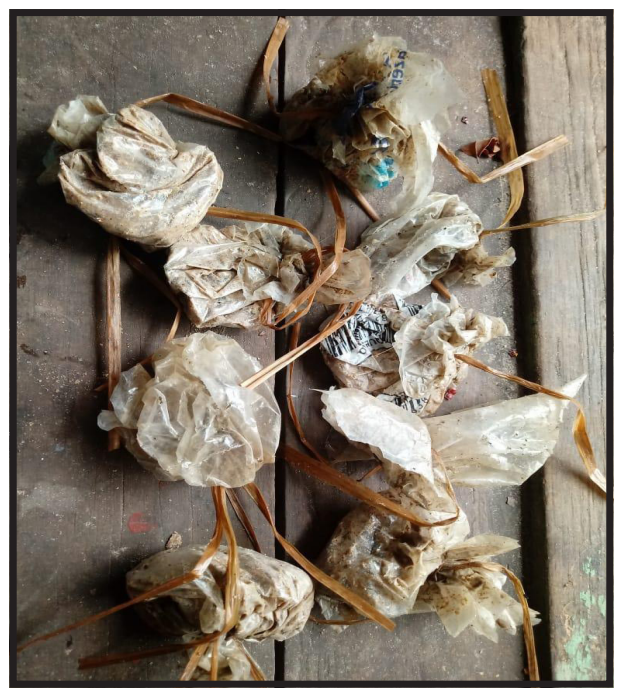

Figura 5 - Farelo de babaçu utilizado como isca na pesca do camarão. Fonte: Os autores (2019).

Os camarões são pescados durante cinco dias ou todos os dias da semana, colocando o matapi em um dia e voltando ao local para buscá-lo no dia seguinte. Com isso, os pescadores afirmam que são capturados em média de 2 a 4 quilos de camarão no período que antecede a safra e na safra de 8 a 10 quilos por dia.

Há diferentes lugares que os pescadores realizam a pesca, como: Areia branca, maré baixa e até mesmo na frente de suas casas. Um total de $63 \%$ afirmou que há lugares onde há uma maior quantidade de camarões, como locais onde a maré está baixa, onde a água não seca por completo ou como eles chamam de lugar "razo". Outros 38\% afirmam que em qualquer lugar colocam seus matapis. Sobre a finalidade da pesca do camarão após a captura, $75 \%$ afirmam que realizam a atividade para consumo e venda, enquanto $13 \%$ apenas para a venda e outros $13 \%$ para o consumo.

A nuvem de palavras abaixo (Figura 6) mostra as respostas dos pescadores para a pergunta sobre qual a melhor estação do ano para realizar a atividade da pesca, na qual todos os entrevistados afirmaram que é o período do inverno. Há destaque para as respostas, "porque dá muito", visto que é um período de colheita em que a espécie está apta a coleta. Além disso, muitos afirmaram que é o período da safra, em que há uma maior quantidade de camarões pescados.

Figura 6 - Nuvem de palavras sobre o melhor período do ano para realizar a pesca do camarão. Fonte: Os autores (2019). 
Em relação ao comércio do camarão, os pescadores afirmam que não há qualquer dificuldade na venda da espécie, devido ser muito apreciado pela população em geral, sendo utilizado em diversos pratos da culinária paraense.

De acordo com os entrevistados, o tamanho dos camarões capturados nos últimos cinco anos diminuiu bastante, associando este fato ao aumento da poluição, ao aumento da população em torno do rio, ao aumento do número de pescadores, à construção de empresas e à falta de esgoto (Figura 7). Essa redução é apontada também nos trabalhos de Silva et al. (2014) e Dias \& Soares (2018), realizadas na ilha de Campopema, no município de Abaetetuba, que mostram que tal diminuição pode ser justificada pelo aumento do número de pescadores, que cresce a cada dia na região.

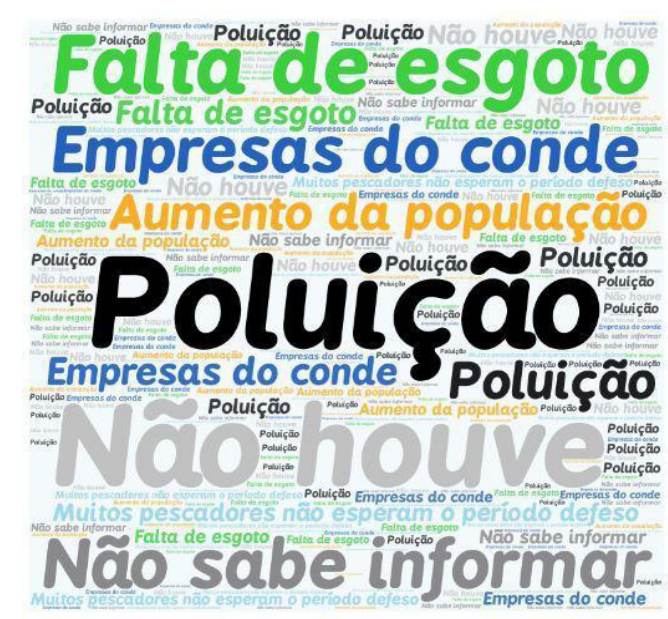

Figura 7 - Nuvem de palavras sobre os motivos para a redução do tamanho do camarão pescado nos últimos anos.

Fonte: Os autores (2019).

Carmo et al. (2015) afirmam que somente os pescadores são capazes de perceber e de apontar os principais impactos pelos quais passa o ambiente em que praticam sua atividade $e$ suas informações são de extrema importância para a tomada de decisões sobre a pesca. Os autores afirmam ainda que os pescadores são os verdadeiros donos do conhecimento ecológico das espécies, que tanto podem favorecer a pescaria quanto pôr em risco a atividade.

Para os pescadores do rio São José, são necessárias medidas para tentar solucionar o problema, como: conscientização da população, diminuição da poluição, a não construção de empresas em torno dos rios e investimento do governo na comunidade (ex: saneamento básico e esgoto) (Figura 8). Percebe-se assim, que muitos se preocupam com uma possível extinção da espécie e, com isso, a perda do seu sustento. Em uma pesquisa realizada por Silva et al. (2014) com pescadores do município de Tucuruí, estes indicam, como medida para a preservação ambiental, o controle da poluição dos rios e o cultivo do camarão em cativeiro, para que assim a atividade possa permanecer.

Com relação a moradia às margens do rio, $38 \%$ dos entrevistados afirmaram ser prejudicial à pesca, contrapondo com $31 \%$ que afirmam que quanto mais casas melhor para o crescimento da comunidade no rio. Outros $25 \%$ afirmam que esse número maior de famílias causa poluição, trazendo prejuízos não só para as famílias que residem como também para a pesca, e 6\% dizem que aumenta o número de pescadores $e$, consequentemente, quanto mais pescadores, maior concorrência na pesca. Esses dados estão de acordo com o observado no trabalho de Lima et al. (2012), cujos entrevistados reconheceram que o número de pescadores aumentou nos últimos anos $e$ as áreas livres para pescar diminuíram, tornando assim a atividade muito concorrida. 


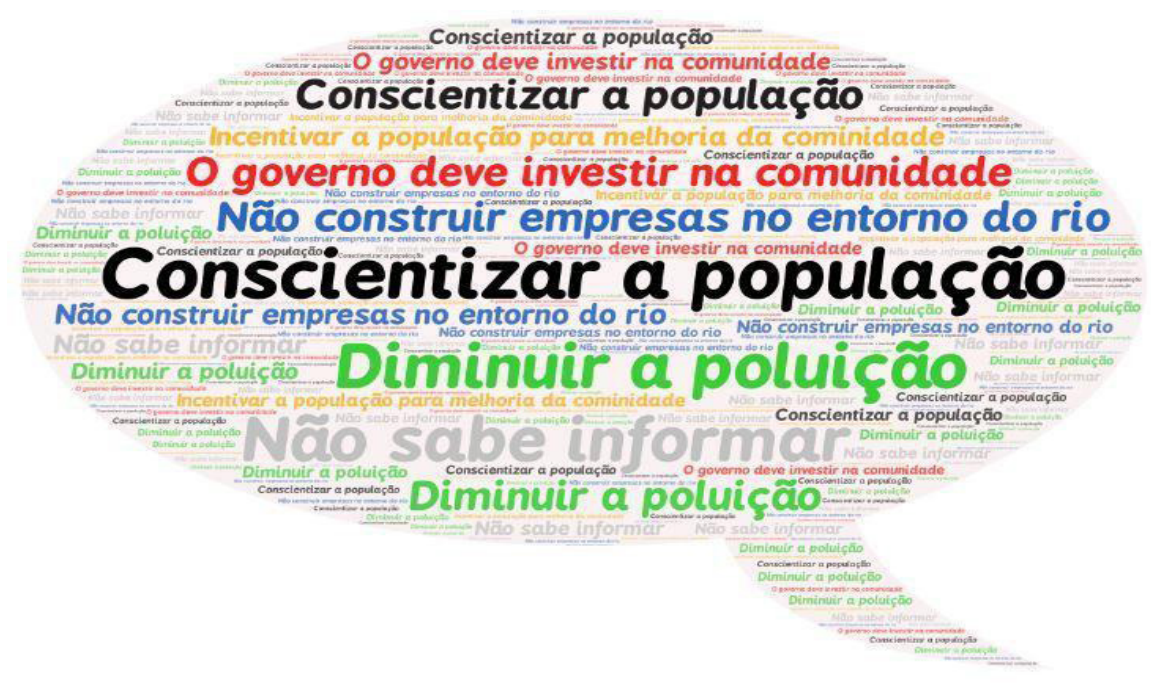

Figura 8 - Nuvem de palavras sobre medidas para tentar solucionar o problema da redução do tamanho do camarão pescado nos últimos anos.

Fonte: Os autores (2019).

\section{Comercialização do camarão-da-amazônia após a pesca}

Após a pesca do camarão, $69 \%$ dos pescadores afirmam que são eles mesmos os responsáveis pela venda, outros $25 \%$ responsabilizam algum membro da família pela atividade. Para $94 \%$, há um grande benefício com a venda do camarão, trazendo dinheiro e renda para suas famílias. A venda ocorre no município de Abaetetuba, na feira livre que fica localizada na frente da cidade, instalada na margem esquerda do rio Maratauíra, onde se vende os mais diversos alimentos como peixe, açaí, verduras, frutas $e$ outros (Barros, 2009).

Para levar o camarão pescado até a cidade, os pescadores utilizam como principal meio de transporte a rabeta (67\%), que é de uso próprio ou compartilhado com qualquer outro pescador, com gastos de combustível diariamente entre $\mathrm{R} \$ 20,00$ e $\mathrm{R} \$ 40,00$ por viagem, havendo assim, dificuldades em relação ao preço do combustível para realizar a venda do pescado.

Em Abaetetuba, a procura pelo produto é significativa, visto que o camarão é utilizado para diversos fins pela população, conforme já descrito no trabalho de Dias \& Soares (2018), sobre a finalidade da pesca na ilha de Campopema, destacando seu uso na preparação de alimentos como o tacacá e o vatapá, entre outros.

\section{Infraestrutura, habitação e saúde dos pescadores}

Todos os entrevistados residem em casas feitas de madeira, sendo cobertas com telhas de barro e piso de madeira. As casas foram construídas nas margens do rio, sobre a terra. De acordo com Nogueira et al. (2017), no estado do Pará, as condições de vida dos pescadores das microrregiões de Cametá, do Salgado e de Bragança são semelhantes.

Dentro das casas dos pescadores, $81 \%$ possuem energia elétrica, enquanto $19 \%$ não possuem. Além disso, $75 \%$ possuem banheiros que se encontram fora da casa, $19 \%$ dentro e $6 \%$ não possuem. O esgoto, de acordo com $94 \%$, é lançado no rio e apenas $6 \%$ possuem fossa séptica. O tratamento de lixo feito pelos moradores é amontoado em um lugar e são em seguida queimados. Tais dados, são semelhantes aos obtidos por Silva et al. (2014), em trabalho realizado com pescadoras na jusante da hidrelétrica de Tucuruí, em que o lixo produzido é geralmente queimado $(87,3 \%)$.

O abastecimento de água dessa população é em sua maior parte $(75 \%)$ feito com a retirada de água do próprio rio, para outros $25 \%$, é feito através de poços artesianos construídos pelos próprios pescadores. No trabalho de Dias \& Soares (2018), foi identificado que cerca de $85 \%$ 
das casas dos homens pescadores são abastecidas com água do rio, enquanto todas as mulheres da pesquisa também obtêm da mesma fonte.

Após o abastecimento de água para suas residências, $63 \%$ dos pescadores afirmam que não fazem nada, enquanto, apenas $19 \%$ fervem, $13 \%$ filtram e $6 \%$ utilizam substâncias como cloro que são colocados na água. Dias \& Soares (2018) verificaram que $86 \%$ dos seus entrevistados afirmam que, após obterem a água, não realizam nenhum procedimento. Já na pesquisa de Silva et al. (2014), a água utilizada para consumo nas residências de mulheres pescadoras é tratada com cloro $(30,9 \%)$, fervida $(25,5 \%)$ ou filtrada $(9,1 \%)$. No entanto, $34,5 \%$ das pescadoras consomem a água sem nenhum tratamento.

A filtração utilizada ocorre através da caixa d'água (Figura 9), que foi construída com o investimento da prefeitura de Abaetetuba para o tratamento de água na comunidade. No entanto, ela abastece somente três casas, do total de vinte residências existentes na localidade, de acordo com os próprios moradores.

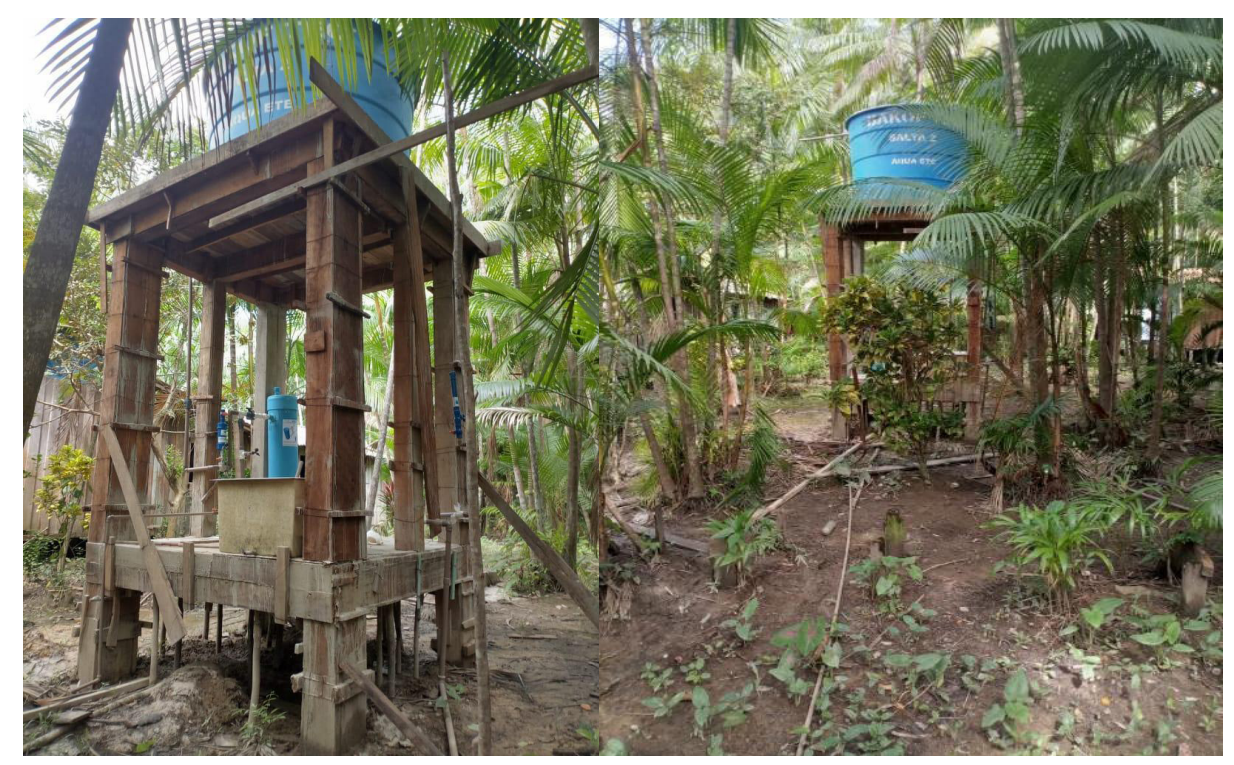

Figura 9 - Caixas d'água para o tratamento da água. Fonte: Os autores (2019).

Em relação à saúde, todos afirmam não haver posto de saúde, mas que recebem visitas de agentes de saúde de Abaetetuba. De acordo com alguns pescadores, essas visitas são feitas raramente, enquanto outros afirmam serem realizadas mensalmente e, dessa forma, os ajudam na prevenção e no tratamento de doenças. Quando não há a visita desses profissionais, os entrevistados afirmam que procuram o hospital ou o posto de saúde no município. Além disso, outros dizem que previnem e tratam algumas enfermidades com o uso de plantas medicinais que eles mesmo extraem na localidade.

A enfermidade que mais se destaca é a alergia, citada por $67 \%$ dos entrevistados, que, de acordo com os pescadores, são coceiras $e$ vermelhidão, seguida de febre e gripe, além de diarreia, vômito e dengue. Tais doenças podem ser justificadas pelo acúmulo de lixo no rio, pela falta de saneamento básico, bem como o não tratamento da água para consumo. Contrapondo os dados, Dias \& Soares (2018) identificaram que as doenças que mais acometem os pescadores do rio Campopema no município de Abaetetuba é a gripe, com $40 \%$, sendo também tratada com remédios caseiros.

Embora os dados não apresentem grandes diferenças, isso pode evidenciar que cada comunidade apresenta suas próprias características relacionadas ao estilo de vida, costumes, tratamento de doenças, saneamento $e$ cuidados com o meio onde vivem. 


\section{Conclusão}

A pesca é um meio de subsistência para muitas famílias ribeirinhas, que encontram nela seu sustento e de sua família, seja para fins alimentícios ou para comercialização. No entanto, este sustento vem sendo ameaçado por diversos fatores que prejudicam não só a atividade, mas também a saúde desses pescadores.

Com a pesquisa, destaca-se que, na visão dos pescadores do rio São José, vários são os fatores socioambientais que influenciam na pesca do camarão-da-amazônia na região, dando ênfase para o aumento da quantidade de pescadores na região, o aumento da atividade pesqueira, a poluição do rio, o saneamento básico inadequado $e$ a falta de respeito ao período de defeso.

A construção de empresas em torno ou próximo ao rio preocupam os pescadores que associam a diminuição da espécie com a poluição trazida por estas. A cada ano, a população em torno do rio aumenta e, dessa forma, cresce o número de pescadores. Além disso, notou-se que alguns destes ainda vivem em condições instáveis, sem saneamento básico, sem água potável e sem tratamento do lixo, o que contribui para a poluição do rio, prejudicando assim a espécie de camarão em estudo.

Portanto, é de grande relevância que sejam realizadas novas pesquisas como esta em outras comunidades vizinhas, para que, assim, possamos ter dados relevantes e comparativos entre estas comunidades, visando que os problemas de uma podem influenciar o desenvolvimento de outra. Além de trabalhos que possam aprofundar-se em investigações relacionadas aos impactos da sobrepesca, considerando índices de captura por unidade de esforço (CPUE), número médio de matapis utilizados por unidade familiar, rendimento médio por matapi, dentre outros.

\section{Referências}

Alcântara GDLC \& Kato HCA. Good handling practices of fresh shrimp sold in street fairs of Belém/PA, Brazil. Journal of Bioenergy and Food Science, 3(1): 139-148, 2016. Disponível em: https://periodicos.ufpa.br/index. php/agroecossistemas/article/view/8966. Acesso em: 25/08/2021.

Araújo MVLF, Silva KCA, Silva BB, Ferreira ILS \& Cintra IHA. Pesca e procedimentos de captura do camarão- da-amazônia a jusante de uma usina hidrelétrica na amazônia brasileira. Biota Amazônia, Macapá, 04(2): 102-112, 2014. Disponível em: https://ppg.revistas. uema.br. Acesso em: 12/04/2019.

Barros FB. Sociabilidade, Cultura e Biodiversidade: Beira de Abaetetuba no Pará. Ciências Sociais Unisinos, São Leopoldo, 45(2): 10, 2009.

Caetano MC. Memória das águas: práticas culturais e educativas de pescadores artesanais nas ilhas de Abaetetuba/PA. 2012. 89 f. Dissertação de PósGraduação - Faculdade de Educação, Universidade Federal do Ceará, Fortaleza, 2012.

Campos AG \& Chaves J V. Seguro defeso: problemas enfrentados pelo programa. Mercado de trabalho, IPEA, 76-84, 2014.

Carmo KA, Filho PAC \& Oliveira TRA. Pesca e o pescador de camarão do baixo São Francisco - o caso da comunidade de ponta mofina, penedo. Revista de Desenvolvimento Econômico - RDE. Salvador/BA, 523-539, 2015.

Costa DAS, Martins JC, Silva KCA, Klatau AGCM \& Cintra IHA. Seletividade do matapi nas capturas de Macrobrachium amazonicum no baixo Rio Tocantins, Amazônia, Brasil. Boletim do Instituto da Pesca, São Paulo, 42(2): 403-417. 2016.

Dias JGG \& Soares RNL. Perfil Socioeconômico de pescadores de Camarão-da-Amazônia Macrobrachium amazonicum (Heller,1862) da ilha de Campopema, município de Abaetetuba/PA, Brasil. Trabalho de Conclusão de Curso - Instituto Federal de Educação, Ciência e Tecnologia do Pará/IFPA - Campus Abaetetuba. 37p. 2018.

FAPESPA - Fundação Amazônica de Amparo a Estudos e Pesquisas. Governo do Estado do Pará. Diretoria de estatística e de tecnologia e gestão da informação. Estatística Municipal: Abaetetuba. 2016. 60. Disponível em: www.parasustentavel.pa.gov.br/wpcontent/uploads/2017/04/Abaetetuba.pdf. Acesso em: 05/05/2018.

IBGE - Instituto Brasileiro de Geografia e Estatística. Dados do Censo Demográfico 2010. Disponível em: <https://www.ibge.gov.br/cidades-e-estados/pa/ abaetetuba.html > Acesso em: 20/05/2019.

Lima MAL, Doria CRC \& Freitas CEC. Pescarias artesanais em comunidades ribeirinhas na Amazônia brasileira: perfil socioeconômico, conflitos e cenário da atividade. Ambiente e sociedade, São Paulo, 15(2): 73-90, 2012.

Lima JF \& Santos TGB. Aspectos econômicos e higiênico-sanitários da comercialização de camarões de água doce em feiras livres de Macapá e Santana, Estado do Amapá. Biota Amazônia, 4: 1-8, 2014. 
Lucena F, Rosa JS, Silva MCN \& Azevedo EF. Population dynamics ofthe River prawn, Macrobrachium amazonicum (Heller, 1862) (Decapoda, Palaemonidae) on Combu island (Amazon estuary). Crustaceana. 2010.

Mérona B, Juras AA, Santos GM \& Cintra IHA. Os peixes e a pesca no baixo rio Tocantins: vinte anos depois da UHE Tucuruí. Eletrobrás Eletronorte, 2010, p. 208.

Moraes SC. Saberes da pesca: uma arqueologia da ciência da tradição. Natal, p. 230, 2005.

Nogueira LSM, Souza DM \& Brígida AMBS. Segurança e saúde dos pescadores artesanais no estado do Pará. São Paulo: Fundacentro, p. 87, 2017.

Oliveira DM \& Frédou FL. 2011. Caracterização e dinâmica espaço-temporal da atividade pesqueira na Baía de Marajó - Estuário Amazônico. Arquivos de Ciência do Mar, Fortaleza, 44(3): 40-53, 2011.

Pinheiro MAA\& HeblingNJ. Biologia de Macrobrachium rosenbergii (De Man, 1879). p.21-46, in Valenti WC (ed.), Carcinicultura de água doce. Tecnologia para produção de camarões. Instituto Brasileiro do Meio Ambiente e dos Recursos Naturais Renováveis, Brasília, 1998.

Ramires M, Barrella W \& Esteves AM. Caracterização da pesca artesanal e o conhecimento pesqueiro local no Vale do Ribeira e Litoral Sul. Revista Ceciliana, São Paulo, 4(1): 37-43, 2012. Disponível em: http://www. unisanta.br/revistaceciliana. Acesso em: 10/03/2019.

Santos GM \& Santos ACM. Sustentabilidade da pesca na Amazônia. Estudos Avançados, 19(54), 2005.
Santos PVCJ, Almeida-Funo ICS, Piga FG, França VL, Torres SA \& Melo CDP. Perfil socioeconômico de pescadores do município da Raposa, estado do Maranhão, Revista Brasileira de Engenharia de Pesca, 6(1): 1-14, 2011. Disponível em: https:/www.sumarios. org/. Acesso em 20/11/2019.

SEMEIA - Secretaria Municipal de Meio Ambiente. Prefeitura de Abaetetuba. Plano Municipal de saneamento: Diagnósticos dos serviços de saneamento. 2017. Disponível em: https://www.abaetetuba.pa.gov. br/secretaria.php?sec=7. Acesso em: 12 nov. 2019.

Silva FNL, da Silva FR, Mangas TP, Oliveira LC, Macedo ARG, Medeiros LR \& Cordeiro CAM. O comércio do camarão da Amazônia (Macrobrachium amazonicum) na cidade de Breves/PA, Brasil. PUBVET. 11(4): 320326, 2017.

Silva JMP \& Silva CN (org.). Pesca e territorialidades: contribuições para a análise espacial da atividade pesqueira. Belém: GAPTA/UFPA, 2011. 305p. Disponível em: http://livroaberto.ufpa.br/jspui/handle/ prefix/134. Acesso em: 23/06/2019.

Silva MB, Silva KCA, Herrmann M, Sousa J, Ramos M, Silva A \& Modesto R. A pesca e o pescador: relatos da experiência vivida na Ilha do Capim, Abaetetuba/ PA. Cadernos de Agroecologia. Anais... do VI CLAA, X CBA e V SEMDF, 13(1), 2014.

Zabotto AR. Estudos sobre impactos ambientais: Uma abordagem contemporânea. Botucatu: FEPAF, p. 293, 2019. Disponível em: http://www.fepaf.org. Acesso em: 22/11/2019.

Zacardi DM, Ponte SCS \& Silva ÁJS. Caracterização da pesca e perfil dos pescadores artesanais de uma comunidade às margens do rio Tapajós, estado do Pará. Belém, Amazônia: Ci. \& Desenv. 10(19): 21, 2014.

Biodiversidade Brasileira - BioBrasil.

Fluxo Contínuo

n. 2, 2022

http://www.icmbio.gov.br/revistaeletronica/index.php/BioBR

Biodiversidade Brasileira é uma publicação eletrônica científica do Instituto Chico Mendes de

Conservação da Biodiversidade (ICMBio) que tem como objetivo fomentar a discussão e a disseminação de experiências em conservação e manejo, com foco em unidades de conservação e espécies ameaçadas.

ISSN: 2236-2886 